Pacific Journal of Mathematics

ON THE VALUES OF A ZETA FUNCTION AT NONPOSITIVE 


\title{
ON THE VALUES OF A ZETA FUNCTION AT NON-POSITIVE INTEGERS
}

\author{
Chong-HSio FANG ANd Minking EIE
}

Let

$$
\tilde{\zeta}(s)=\sum_{g_{1}=1}^{\infty} \sum_{g_{2}=1}^{\infty} \sum_{g_{3}=0}^{\infty}\left[g_{1} g_{2}+\left(g_{1}+g_{2}\right) g_{3}\right]^{-s}, \quad \operatorname{Re} s>\frac{3}{2},
$$

be the zeta function associated with the principal Delaunay-Voronoi cone. A general theory asserts that $\tilde{\zeta}(s)$ has an analytic continuation which is holomorphic in the whole complex plane except possible poles at $s=3 / 2, s=1$ and $s=1 / 2$. In this paper, we shall compute the values of $\tilde{\zeta}(s)$ at non-positive integers. It is not surprising to see that these values are rational numbers and can be expressed explicitly in terms of Bernoulli numbers; i.e.

$$
\tilde{\zeta}(-m)=-\frac{1}{2}\left(\frac{B_{m+1}}{m+1}\right)^{2}+(-1)^{m+1} \frac{B_{2 m+2}\left(1+2^{2 m+2}\right)}{2^{2 m+1}(2 m+2)^{2}}+\frac{\delta_{0 m}}{4} .
$$

1. Introduction and the main theorem. Let

$$
\tilde{\zeta}(s)=\sum_{g_{1}=1}^{\infty} \sum_{g_{2}=1}^{\infty} \sum_{g_{3}=0}^{\infty}\left[g_{1} g_{2}+\left(g_{1}+g_{2}\right) g_{3}\right]^{-s}, \quad \operatorname{Re} s>3 / 2,
$$

be the zeta function associated with the principal Delaunay-Voronoi cone $\Omega$ (see [5]) as defined by

$$
\Omega=\left\{\left[\begin{array}{cc}
\lambda_{1}+\lambda_{3} & -\lambda_{3} \\
-\lambda_{3} & \lambda_{2}+\lambda_{3}
\end{array}\right] \mid \lambda_{1}, \lambda_{2}, \lambda_{3} \geq 0\right\}
$$

By the general theory as in [7], this zeta function is absolutely convergent for $\operatorname{Re} s>3 / 2$ and hence it defines a holomorphic function of a complex variable $s$. Furthermore, $\tilde{\zeta}(s)$ has an analytic continuation which is holomorphic in the whole complex plane except possible poles at $s=3 / 2, s=1$ and $s=1 / 2$.

In this paper, we shall prove the following

MAIN TheOREM. For any integer $m$ with $m \geq 0, \tilde{\zeta}(-m)$ is a rational number. More precisely,

$$
\tilde{\zeta}(-m)=-\frac{1}{2}\left(\frac{B_{m+1}}{m+1}\right)^{2}+(-1)^{m+1} \frac{B_{2 m+2}\left(1+2^{2 m+2}\right)}{2^{2 m+1}(2 m+2)^{2}}+\frac{\delta_{0 m}}{4} .
$$


Here $\delta_{0 m}$ is the Kronecker delta function and the Bernoulli numbers $B_{m}(m \geq 1)$ are defined by

$$
\left\{\begin{array}{l}
\frac{t}{e^{t}-1}=1+\sum_{m=1}^{\infty} \frac{B_{m} t^{m}}{m !}, \quad|t|<2 \pi, \\
B_{0}=1 .
\end{array}\right.
$$

2. The integral expression of $\tilde{\zeta}(s)$. To obtain an integral expression for $\tilde{\zeta}(s) \Gamma(s) \Gamma\left(s-\frac{1}{2}\right) \pi^{1 / 2}$, we need the following lemma.

LEMMA 1. Let $Y$ be the variable of $2 \times 2$ real symmetric matrix, and $G$ be a $2 \times 2$ positive definite symmetric matrix. Then we have, for $\operatorname{Re} s \geq 3 / 2$,

$$
\int_{Y>0}(\operatorname{det} Y)^{s-3 / 2} e^{-\operatorname{tr}(Y G)} d Y=(\operatorname{det} G)^{-s} \pi^{1 / 2} \Gamma(s) \Gamma(s-1 / 2) .
$$

Here $Y>0$ means that $Y$ is positively definite.

Proof. See p. 226 of [1].

Proposition 1. For $\operatorname{Re} s>3 / 2$, we have

$$
\begin{aligned}
\tilde{\zeta}(s) \Gamma(s) \Gamma(s-1 / 2) \pi^{1 / 2} & \\
= & 2 \int_{0}^{\infty} u^{2 s-4} d u \int_{0}^{1}\left(1-r^{2}\right)^{s-3 / 2} r d r \\
& \times \int_{0}^{2 \pi} u^{3}\left[\left(e^{u(1+r \sin \theta)}-1\right)\right. \\
& \left.\times\left(e^{u(1-r \sin \theta)}-1\right)\left(1-e^{-2 u(1-r \cos \theta)}\right)\right]^{-1} d \theta .
\end{aligned}
$$

Proof. For $\operatorname{Re} s>3 / 2$, by Lemma 1 , we have

$$
\begin{gathered}
\tilde{\zeta}(s) \Gamma(s) \Gamma(s-1 / 2) \pi^{1 / 2} \\
=\sum_{g_{1}=1}^{\infty} \sum_{g_{2}=1}^{\infty} \sum_{g_{3}=0}^{\infty} \int_{Y>0}(\operatorname{det} Y)^{s-3 / 2} \exp \left\{-y_{1} g_{1}-y_{2} g_{2}\right. \\
=\int_{Y>0}(\operatorname{det} Y)^{s-3 / 2}\left[\left(e^{y_{1}}-1\right)\left(e^{y_{2}}-1\right)\right. \\
\left.\times\left(1-e^{-y_{1}-y_{2}+2 y_{12}}\right)\right]^{-1} d y_{1} d y_{2} d y_{12} .
\end{gathered}
$$

By changing of variables: $u=\left(y_{1}+y_{2}\right) / 2, v=\left(y_{1}-y_{2}\right) / 2, w=y_{12} ; ?$ the integral is transformed into

$$
\begin{aligned}
2 \int_{u^{2}-v^{2}-w^{2}>0, u>0} & \left(u^{2}-v^{2}-w^{2}\right)^{s-3 / 2} \\
& \times\left[\left(e^{u+v}-1\right)\left(e^{u-v}-1\right)\left(1-e^{-2 u+2 w}\right)\right]^{-1} d u d v d w .
\end{aligned}
$$


Let $v=u p, w=u q$ and let $p=r \sin \theta, q=r \cos \theta$. Then

$$
\begin{aligned}
\tilde{\zeta}(s) \Gamma(s) \Gamma(s-1 / 2) \pi^{1 / 2} & \\
=2 & \int_{0}^{\infty} u^{2 s-4} d u \int_{0}^{1}\left(1-r^{2}\right)^{s-3 / 2} r d r \\
& \times \int_{0}^{2 \pi} u^{3}\left[\left(e^{u(1+r \sin \theta)}-1\right)\left(e^{u(1-r \sin \theta)}-1\right)\right. \\
& \left.\times\left(1-e^{-2 u(1-r \cos \theta)}\right)\right]^{-1} d \theta
\end{aligned}
$$

as asserted.

Let

$$
\begin{array}{r}
F(u, r)=\int_{0}^{2 \pi} u^{3}\left[\left(e^{u(1+r \sin \theta)}-1\right)\left(e^{u(1-r \sin \theta)}-1\right)\right. \\
\left.\quad \times\left(1-e^{-2 u(1-r \cos \theta)}\right)\right]^{-1} d \theta
\end{array}
$$

and

$$
I(s, u, F)=\frac{1}{\Gamma(s-1 / 2) \pi^{1 / 2}} \int_{0}^{1}\left(1-r^{2}\right)^{s-3 / 2} r F(u, r) d r .
$$

$I(s, u, F)$ as a function of $s$, is holomorphic for all $s \neq 1$ since it is a quotient of two generalized functions in $s$ which has simple poles at negative half integers [7].

Denote by $L(\varepsilon)$ the contour in the complex plane consisting of the interval $[\varepsilon,+\infty)$ twice, in both directions (in and out) and the circle $|z|=\varepsilon$ in counterclockwise direction. Then the integral expression of $\tilde{\zeta}(s) \Gamma(s)$ can be transformed into a contour integral of the form

$$
2\left(e^{4 \pi i s}-1\right)^{-1} \int_{L(\varepsilon)} u^{2 s-4} I(s, u, F) d u .
$$

With the functional equation of gamma function $\Gamma(s) \Gamma(1-s)=$ $2 \pi i e^{\pi i s}\left(e^{2 \pi i s}-1\right)^{-1}$, we get

$$
\tilde{\zeta}(s)=2 \Gamma(1-s) e^{-\pi i s}\left(e^{4 \pi i s}-1\right)^{-1} \frac{1}{2 \pi i} \int_{L(\varepsilon)} u^{2 s-4} I(s, u, F) d u .
$$

This gives the analytic continuation of $\tilde{\zeta}(s)$.

Proposition 2. For all $s \in C-\{ \pm 1 / 2, \pm 3 / 2, \ldots\}$, we have

$$
\tilde{\zeta}(s)=2 \Gamma(1-s) e^{-\pi i s}\left(e^{2 \pi i s}+1\right)^{-1} \frac{1}{2 \pi i} \int_{L(\varepsilon)} u^{2 s-4} I(s, u, F) d u
$$

where

$$
I(s, u, F)=\frac{1}{\Gamma(s-1 / 2) \pi^{1 / 2}} \int_{0}^{1}\left(1-r^{2}\right)^{s-3 / 2} r F(u, r) d r
$$


with

$$
\begin{aligned}
F(u, r)=\int_{0}^{2 \pi} u^{3}\left[\left(e^{u(1+r \sin \theta)}-1\right)\left(e^{u(1-r \sin \theta)}-1\right)\right. & \\
& \left.\times\left(1-e^{-2 u(1-r \cos \theta)}\right)\right]^{-1} d \theta .
\end{aligned}
$$

REMARK. From the analytic continuation of $\tilde{\zeta}(s)$ given in Proposition 2 , it seems that it might also have possible poles at negative half integers. However these poles can be eliminated by the gamma function appearing in the expression of $I(s, u, F)$. In fact, $\tilde{\zeta}(s)$ is analytic at negative half integers; but it is hard to see from our formula.

3. The values of $\tilde{\zeta}(s)$ at non-positive integers. The analytic continuation of $I(s, u, F)$ was given in a more general context in [3]. When $s$ is a non-positive integer, the value $\tilde{\zeta}(s)$ depends only on the continuation of $I(s, u, F)$ when $|u|<\varepsilon$, due to the fact that the contour integral along $[\varepsilon,+\infty]$ twice in opposite direction cancel each other. Furthermore, these values can be obtained by the theorem of residue.

Proposition 3. The values of $\tilde{\zeta}(s)$ at $s=0,-1,-2, \ldots$, $-m, \ldots$, are rational numbers and

$$
\tilde{\zeta}(-m)=-\frac{\Gamma(2 m+2)}{2^{2 m+1} \pi} N(-m)
$$

where

$$
N(s)=\int_{0}^{1}\left(1-r^{2}\right)^{s-3 / 2} r d r \int_{0}^{2 \pi} Q_{2 m+3}(r, \theta) d \theta, \quad \operatorname{Re} s>1,
$$

with

$$
\begin{aligned}
& Q_{2 l+1}(r, \theta) \\
& \begin{aligned}
=\frac{1}{2} \sum_{k=0}^{l} \frac{B_{2(l-k)} B_{2 k}}{(2 l-2 k) !(2 k) !} & {\left[(1+r \sin \theta)^{2 l-2 k-1}(1-r \sin \theta)^{2 k-1}\right.} \\
& -(1+r \sin \theta)^{2 l-2 k-1}(2-2 r \cos \theta)^{2 k-1} \\
& \left.-(1-r \sin \theta)^{2 l-2 k-1}(2-2 r \cos \theta)^{2 k-1}\right]
\end{aligned} \\
& +\frac{1}{8} \delta_{1 l} \quad\left(\delta_{i j} \text { is the Kronecker's delta function }\right) .
\end{aligned}
$$

Proof. We have

$$
\tilde{\zeta}(-m)=2 \Gamma(1+m)(-1)^{m-1} \frac{1}{2 \pi i} \int_{L(\varepsilon)} u^{-2 m-4} I(-m, u, F) d u .
$$


In order to compute $\tilde{\zeta}(-m)$, we must find the coefficient of $u^{2 m+3}$ in the power expansion of $I(-m, u, F)$. For $|u|<\pi / 2$, we have

$$
\begin{aligned}
\frac{u}{e^{u(1+r \sin \theta)}-1} & =\frac{1}{1+r \sin \theta}-\frac{u}{2}+\sum_{n=1}^{\infty} \frac{B_{2 n}(1+r \sin \theta)^{2 n-1} u^{2 n}}{(2 n) !} \\
\frac{u}{e^{u(1-r \sin \theta)}-1} & =\frac{1}{1-r \sin \theta}-\frac{u}{2}+\sum_{n=1}^{\infty} \frac{B_{2 n}(1-r \sin \theta)^{2 n-1} u^{2 n}}{(2 n) !} \\
\frac{u}{1-e^{-2 u(1-r \cos \theta)}} & =\frac{1}{1-r \cos \theta}-\frac{u}{2}+\sum_{n=1}^{\infty} \frac{B_{2 n}(2+2 r \cos \theta)^{2 n-1} u^{2 n}}{(2 n) !}
\end{aligned}
$$

The coefficient of $u^{2 m+3}$ in the power expansion of

$$
u^{3}\left[\left(e^{u(1+r \sin \theta)}-1\right)\left(e^{u(1-r \sin \theta)}-1\right)\left(1-e^{-2 u(1-r \cos \theta)}\right]^{-1}\right.
$$

is $Q_{2 m+3}(r, \theta)$, which is a $Q$-linear combination of functions of following types:

$$
\begin{aligned}
& F_{1}(r, \theta)=(1+r \sin \theta)^{m_{11}-1}(1-r \sin \theta)^{m_{12}}(1-r \cos \theta)^{m_{13}}, \\
& F_{2}(r, \theta)=(1+r \sin \theta)^{m_{21}}(1-r \sin \theta)^{m_{22}-1}(1-r \cos \theta)^{m_{23}}, \\
& F_{3}(r, \theta)=(1+r \sin \theta)^{m_{31}}(1-r \sin \theta)^{m_{32}}(1-r \cos \theta)^{m_{33}-1},
\end{aligned}
$$

where $m_{i j}(i, j=1,2,3)$ are positive integers or zero. Integrating with respect to $\theta$ from 0 to $2 \pi$, we get

$$
\begin{aligned}
\int_{0}^{2 \pi} F_{j}(r, \theta) d \theta & =2 \pi P_{j}\left(r^{2}\right) \quad \text { if } m_{j j} \geq 1, \\
& =\frac{2 \pi Q_{j}\left(r^{2}\right)}{\sqrt{1-r^{2}}}+2 \pi R_{j}\left(r^{2}\right) \text { if } m_{j j}=0,
\end{aligned}
$$

where $P_{j}(X), Q_{j}(X)$ and $R_{j}(x)$ are polynomials. Thus the coefficient of $u^{2 m+3}$ in $I(-m, u, F)$ is a $Q$-linear combination of integrals of the forms

$$
\begin{aligned}
& \frac{2 \pi}{\Gamma(-m-1 / 2) \pi^{1 / 2}} \int_{0}^{1}\left(1-r^{2}\right)^{-m-3 / 2} r P_{j}\left(r^{2}\right) d r \\
& \frac{2 \pi}{\Gamma(-m-1 / 2) \pi^{1 / 2}} \int_{0}^{1}\left(1-r^{2}\right)^{-m-2} r Q_{j}\left(r^{2}\right) d r .
\end{aligned}
$$

The values of continuations of these integrals are rational numbers. Consequently, the value $\tilde{\zeta}(-m)$ is a rational number. 
4. On the explicit values of $N(-m)$ and the proof of the main theorem. In this section, we shall prove that almost all terms in $Q_{2 m+3}(r, \theta)$ have zero contribution to $N(-m)$. The contributions from remaining terms will be computed one by one. Finally, we obtain the explicit expression of $\tilde{\zeta}(-m)$ as shown in Main Theorem.

Proposition 4. For non-negative integers $p$ and $q$, not both 0 , define

$F_{p, q}(s)=\int_{0}^{1}\left(1-r^{2}\right)^{s-3 / 2} r d r \int_{0}^{2 \pi}(1+r \sin \theta)^{2 p-1}(1-r \sin \theta)^{2 q-1} d \theta$

$(\operatorname{Re} s>1)$.

Then $F_{p, q}(s)$ is a rational function with simple poles at $s=\frac{1}{2},-\frac{1}{2}$, $\ldots, \frac{3}{2}-p-q$ (and also at $s=1$ if $p$ or $q$ is zero) and vanishes at $s=1-p-q$ unless $p=q$, in which case

$$
F_{p, p}(1-2 p)=-2 \pi(4 p-2)(4 p-4) \cdots 2 /(4 p-1)(4 p-3) \cdots 3 .
$$

Proof. Changing from polar coordinate to linear coordinate, $r \cos \theta$ $=x, r \sin \theta=y$; we find

$$
F_{p, q}(s)=\iint_{x^{2}+y^{2}<1}(1+y)^{2 p-1}(1-y)^{2 q-1}\left(1-x^{2}-y^{2}\right)^{s-3 / 2} d x d y .
$$

With $t=x / \sqrt{1-y^{2}}$ as a new variable in place of $x$, then

$$
\begin{aligned}
F_{p, q}(s)= & \int_{-1}^{1}(1+y)^{s+2 p-2}(1-y)^{s+2 q-2} d y \int_{-1}^{1}\left(1-t^{2}\right)^{s-3 / 2} d t \\
= & 2^{2 s+2 p+2 q-3} \int_{0}^{1} u^{s+2 p-2}(1-u)^{s+2 q-2} d u \\
& \times \int_{0}^{1} v^{-1 / 2}(1-v)^{s-3 / 2} d v \quad\left(u=\frac{y+1}{2}, v=t^{2}\right) \\
= & 2^{2 s+2 p+2 q-3} \frac{\Gamma(s+2 p-1) \Gamma(s+2 q-1) \Gamma(s-1 / 2) \Gamma(1 / 2)}{\Gamma(2 s+2 p+2 q-2) \Gamma(s)} .
\end{aligned}
$$

This explicit evaluation holds for any complex number $p$ and $q$ (and $\operatorname{Re} s$ sufficiently). The statements of the proposition follow easily when $p$ and $q$ are non-negative integers: it is clear that the poles are as stated and that $F_{p, q}(1-p-q)=0$ for $p \neq q$, since in that case both $\Gamma(s)$ and $\Gamma(2 p+2 q+2 s-2)$; but only one of $\Gamma(2 p+s-1)$ and $\Gamma(2 q+s-1)$, have simple poles at $s=1-p-q$, while for $p=q$ all 
four of these gamma functions have poles and we obtain the formula given in the proposition by comparing residues.

Proposition 5. For non-negative integers $p$ and $q$, not both 0 , define

$$
G_{p, q}(s)=\int_{0}^{1}\left(1-r^{2}\right)^{s-3 / 2} r d r \int_{0}^{2 \pi}(1-r \cos \theta)^{2 p-1}(1-r \sin \theta)^{2 q-1} d \theta
$$

$(\operatorname{Re} s>1)$.

Then $G_{p, q}(s)$ is a rational function with simple poles at $s=\frac{1}{2},-\frac{1}{2}$, $\ldots, \frac{5}{2}-p-q$ (and also at $s=1,0, \ldots, 2-p-q$ if $p$ or $q$ is zero) and vanishes at $s=1-p-q$ unless $p=q$ or $p$ or $q$ is zero, in which case

$$
G_{p, q}(1-p-q)=\left\{\begin{array}{l}
-2^{p}(p-1) ! \pi /(4 p-1)(4 p-3) \cdots(2 p+1), \\
(-1)^{p+q} \pi /(p+q), \quad \text { if } p=0 \text { or } q=0, \\
0, \quad \text { otherwise. }
\end{array}\right.
$$

Proof. We have

$$
G_{p, q}(s)=\iint_{x^{2}+y^{2}<1}(1-x)^{2 p-1}(1-y)^{2 q-1}\left(1-x^{2}-y^{2}\right)^{s-3 / 2} d x d y
$$

Suppose that $p \geq 1$ and expand $(1-x)^{2 p-1}$ by the binomial theorem. Then $G_{p, q}(s)$ is a sum of double integrals with an inner integral of the form

$$
\int_{-a}^{a} x^{m}\left(a^{2}-x^{2}\right)^{s-3 / 2} d x \quad\left(a=\sqrt{1-y^{2}}\right),
$$

which is 0 for odd $m$. For $m=2 j$, we have

Hence

$$
\int_{-a}^{a} x^{2 j}\left(a^{2}-x^{2}\right)^{s-3 / 2} d x=\frac{\Gamma(j+1 / 2) \Gamma(s-1 / 2) a^{2 j+2 s-2}}{\Gamma(s+j)} .
$$

$$
\begin{aligned}
G_{p, q}(s)= & \sum_{j=0}^{p-1}\left(\begin{array}{c}
2 p-1 \\
2 j
\end{array}\right) \frac{\Gamma(s-1 / 2) \Gamma(j-1 / 2}{\Gamma(s+j)} \\
& \cdot \int_{-1}^{1}(1-y)^{s+2 q-j-2}(1+y)^{s+j-1} d y \\
= & \sum_{j=0}^{p-1} \frac{(2 p-1) ! \pi}{2^{2 j} j !(2 p-2 j-1) !} \cdot \frac{\Gamma(s-1 / 2)}{\Gamma(s+q+j-1 / 2)} \\
& \cdot \frac{\Gamma(s+2 q+j-1)}{\Gamma(s+q+j)} .
\end{aligned}
$$


The second factor in the $j$ th summand has poles at half integers between $\frac{1}{2}$ and $\frac{3}{2}-q-j \geq \frac{5}{2}-p-q$. The third factor in the $j$ th summand is a polynomial (unless $q=0$, when it equals $1 /(s+j-1)$ ) which vanishes at $s=1-p-q$ for all $j$ if $q>p$ and for all $j$ except $j=0$ if $q=p$. This leads to the assertions of the proposition. When $p>q=0$, the value of $G$ at $s=1-p-q$ is given by

$$
\begin{aligned}
G_{p, 0}(1-p)= & \sum_{j=0}^{p-1} \frac{(2 p-1) ! \pi}{2^{2 j} j !(2 p-2 j-1) !} \\
& \cdot(-1)^{j} \frac{\Gamma(p-j+1 / 2)}{\Gamma(p+1 / 2)} \cdot \frac{-1}{p+j} \\
= & \pi \sum_{j=0}^{p-1} \frac{(-1)^{j+1}(p-1) !}{j !(p-j) !}=\frac{(-1)^{p} \pi}{p} .
\end{aligned}
$$

The proof of the main theorem. Note that the function $N(s)$ in Proposition 3 is a linear combination of $F_{p, q}(s)$ and $G_{p, q}(s)$ with $p+q=m+1$. More precisely, we have

$$
\begin{gathered}
N(s)=\frac{1}{2} \sum_{p+q=m+1,0 \leq p \leq m+1} \frac{B_{2 p} B_{2 q}}{(2 p) !(2 q) !}\left[F_{p, q}(s)-2^{2 p} G_{p, q}(s)\right] \\
+\frac{\delta_{0 m}}{8(s-1 / 2)} .
\end{gathered}
$$

If $m$ is a positive even integer, then $p \neq q$. Since

$$
\begin{aligned}
& F_{p, q}(-m)=F_{p, q}(1-p-q)=0, \quad \text { for } p \neq q, \\
& G_{p, q}(-m)=G_{p, q}(1-p-q)=0, \quad \text { for } p \neq q, p \neq 0, q \neq 0
\end{aligned}
$$

it follows

$$
\begin{aligned}
N(-m) & =\frac{B_{2 m+2}}{2(2 m+2) !}\left[-2^{2 m+2} G_{m+1,0}(-m)-G_{0, m+1}(-m)\right] \\
& =\frac{(-1)^{m} B_{2 m+2}\left(2^{2 m+2}+1\right) \pi}{(2 m+2)(2 m+2) !}
\end{aligned}
$$


If $m$ is a positive odd integer, then it is possible that $p=q=$ $(m+1) / 2$. Hence

$$
\begin{aligned}
N(-m)= & \frac{B_{2 m+2}}{2(2 m+2) !}\left[-2^{2 m+2} G_{m+1,0}(-m)-G_{0, m+1}(-m)\right] \\
& +\frac{1}{2}\left(\frac{B_{2 m+1}}{(m+1)}\right)^{2}\left[F_{(m+1) / 2,(m+1) / 2}(-m)\right. \\
= & \frac{(-1)^{m} B_{2 m+2}\left(2^{2 m+2}+1\right) \pi}{(2 m+2)(2 m+2) !} \\
& +\frac{1}{2}\left(\frac{B_{2 m+1}}{(m+1) !}\right)^{2}\left\{\frac{-2 \pi\left(2^{m} m !\right)^{2}}{(2 m+1) !}+\frac{4 \pi\left(2^{m} m !\right)^{2}}{(2 m+1) !}\right\} \\
= & \frac{(-1)^{m} B_{2 m+2}\left(2^{2 m+2}+1\right) \pi}{(2 m+2)(2 m+2) !}+\frac{1}{2}\left(\frac{B_{2 m+1}}{m+1}\right)^{2} \cdot \frac{2^{2 m+1} \pi}{(2 m+1) !} .
\end{aligned}
$$

But $B_{l}=0$ if $l$ is a positive odd integer greater than 1 . Consequently, we have for any positive integer $m$,

$$
N(-m)=\frac{(-1)^{m} B_{2 m+2}\left(2^{2 m+2}+1\right) \pi}{(2 m+2)(2 m+2) !}+\frac{1}{2}\left(\frac{B_{2 m+1}}{m+1}\right)^{2} \cdot \frac{2^{2 m+1} \pi}{(2 m+1) !} .
$$

Hence

$$
\begin{aligned}
\tilde{\zeta}(-m) & =-\frac{(2 m+1) !}{2^{2 m+1} \pi} N(-m) \\
& =-\frac{1}{2}\left(\frac{B_{2 m+1}}{m+1}\right)^{2}+\frac{(-1)^{m+1} B_{2 m+2}\left(2^{2 m+2}+1\right)}{2^{2 m+1}(2 m+2)^{2}} .
\end{aligned}
$$

For the case $m=0$, a direct computation from Proposition 3 yields

$$
\tilde{\zeta}(0)=\frac{1}{48} \text {. }
$$

Acknowledgment. The authors wish to thank the helpful suggestions from the referee.

\section{REFERENCES}

[1] W. L. Baily, Jr., Introductory Lectures on Automorphic Forms, Princeton University Press (1973).

[2] Minking Eie, A zeta-function associated with zero ternary forms, Proc. Amer. Math. Soc., 94 (1985), 387-392.

[3] A. Kurihara, On the values at non-positive integers of Siegel's zeta functions of $Q$-anisotropic quadratic forms with signature $(1, n-1)$, J. Fac. Sci. University of Tokyo. Sect. 1A Math., 28 (1981), 567-584. 
[4] H. Mellin, Eine Formel für den Logarithmus transcendenter Functionen von endlichen Geschlecht, Acta Soc. Sci. Fennicae, 29 (1900), 3-49.

[5] Y. Namikawa, Toroidal Compactification of Siegel Spaces, Springer-Verlag Lecture Notes in Math. 812 .

[6] _ A new compactification of Siegel space and degeneration of abelian varieties. I, Math. Annalen, 221 (1976), 97-141.

[7] I. Satake, Special values of zeta functions associated with self dual homogeneous cones, manuscript (1981).

[8] I. M. Gelfand and G. E. Shilov, Generalized Functions, Vol. I: Properties and Operations, Academic Press, New York, 1964.

[9] M. Sato, and T. Shintani, On zeta functions associated with prehomogeneous vector spaces, Ann. of Math., 100 (1974), 131-170.

[10] T. Shintani, Zeta-functions associated with the vector of quadratic forms, J. Fac. Sci. University of Tokyo. Sect. 1A Math., 22 (1975), 25-65.

[11] _ On evaluation of zeta functions of totally real algebraic number fields at non-positive integers, J. Fac. Sci. University of Tokyo, 23 (1976), 393-417.

Received September 19, 1988 and in revised form April 20, 1989. Research supported by Institute of Math. Academia Sinica and N.S.C. of Taiwan, Republic of China.

INSTITUTE OF MATHEMATICS

ACADEMia Sinica

NANKANG, TAIPEI 11529

TAIWAN, Republic OF China 


\title{
PACIFIC JOURNAL OF MATHEMATICS EDITORS
}

\author{
V. S. VARADARAJAN \\ (Managing Editor) \\ University of California \\ Los Angeles, CA 90024-1555-05 \\ Herbert Clemens \\ University of Utah \\ Salt Lake City, UT 84112 \\ ThOMAS ENRIGHT \\ University of California, San Diego \\ La Jolla, CA 92093
}

R. FINN

Stanford University

Stanford, CA 94305

HeRmanN FlaschKa

University of Arizona

Tucson, AZ 85721

VAUGHaN F. R. Jones

University of California

Berkeley, CA 94720

Steven Kerckhoff

Stanford University

Stanford, CA 94305

\section{C. MOORE}

University of California

Berkeley, CA 94720

MaRTin SCHARLEMANN

University of California

Santa Barbara, CA 93106

HAROLD STARK

University of California, San Diego

La Jolla, CA 92093

\section{ASSOCIATE EDITORS}
R. ARENS
E. F. BECKENBACH (1906-1982)
B. H. NeumanN
F. WOLF
(1904-1989)
K. YosHidA

\section{SUPPORTING INSTITUTIONS}

UNIVERSITY OF ARIZONA
UNIVERSITY OF BRITISH COLUMBIA
CALIFORNIA INSTITUTE OF TECHNOLOGY
UNIVERSITY OF CALIFORNIA
MONTANA STATE UNIVERSITY
UNIVERSITY OF NEVADA, RENO
NEW MEXICO STATE UNIVERSITY
OREGON STATE UNIVERSITY
UNIVERSITY OF ARIZONA
UNIVERSITY OF BRITISH COLUMBIA UNIVERSITY OF CALIFORNIA
MONTANA STATE UNIVERSITY
NEW MEXICO STATE UNIVERSITY

\author{
UNIVERSITY OF SOUTHERN CALIFORNIA \\ STANFORD UNIVERSITY \\ UNIVERSITY OF HAWAII \\ UNIVERSITY OF TOKYO \\ UNIVERSITY OF UTAH \\ WASHINGTON STATE UNIVERSITY \\ UNIVERSITY OF WASHINGTON
}
UNIVERSITY OF OREGON

The Supporting Institutions listed above contribute to the cost of publication of this Journal, but they are not owners or publishers and have no responsibility for its content or policies.

\begin{abstract}
Mathematical papers intended for publication in the Pacific Journal of Mathematics should be in typed form or offset-reproduced (not dittoed), double spaced with large margins. Please do not use built up fractions in the text of the manuscript. However, you may use them in the displayed equations. Underline Greek letters in red, German in green, and script in blue. The first paragraph must be capable of being used separately as a synopsis of the entire paper. In particular it should contain no bibliographic references. Please propose a heading for the odd numbered pages of less than 35 characters. Manuscripts, in triplicate, may be sent to any one of the editors. Please classify according to the 1980 Mathematics Subject Classification (1985 Revision) scheme which can be found in the December index volumes of Mathematical Reviews. Supply name and address of author to whom proofs should be sent. All other communications should be addressed to the managing editor, or Elaine Barth, University of California, Los Angeles, California 90024-1555-05.

There are page-charges associated with articles appearing in the Pacific Journal of Mathematics. These charges are expected to be paid by the author's University, Government Agency or Company. If the author or authors do not have access to such Institutional support these charges are waived. Single authors will receive 50 free reprints; joint authors will receive a total of 100 free reprints. Additional copies may be obtained at cost in multiples of 50 .
\end{abstract}

The Pacific Journal of Mathematics (ISSN 0030-8730) is published monthly. Regular subscription rate: $\$ 190.00$ a year (12 issues). Special rate: $\$ 95.00$ a year to individual members of supporting institutions.

Subscriptions, orders for numbers issued in the last three calendar years, and changes of address should be sent to Pacific Journal of Mathematics, P.O. Box 969, Carmel Valley, CA 93924, U.S.A. Old back numbers obtainable from Kraus Periodicals Co., Route 100, Millwood, NY 10546.

The Pacific Journal of Mathematics at P.O. Box 969, Carmel Valley, CA 93924 (ISSN 0030-8730) is published monthly. Second-class postage paid at Carmel Valley, California 93924, and additional mailing offices. Postmaster: send address changes to Pacific Journal of Mathematics, P.O. Box 969, Carmel Valley, CA 93924.

\section{PUBLISHED BY PACIFIC JOURNAL OF MATHEMATICS, A NON-PROFIT CORPORATION}




\section{Pacific Journal of Mathematics}

Vol. 145, No. $2 \quad$ October, 1990

Chong Hsio Fang and Minking Eie, On the values of a zeta function at

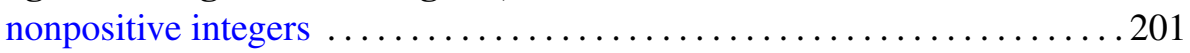

Howard D. Fegan, Brian F. Steer and L. Whiteway, Spectral symmetry of the Dirac operator for compact and noncompact symmetric pairs ..... 211

William James Heinzer and David C. Lantz, Integral domains that lose

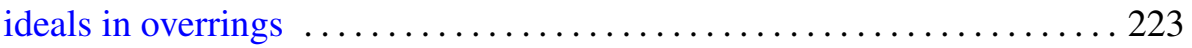

Alexander Eben Koonce, Relations among generalized characteristic classes .......................................239

M. S. Narasimhan and Günther Trautmann, Compactification of

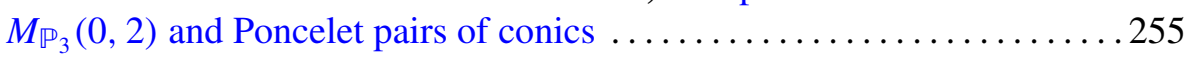

James Alexander Reeds, III and Lawrence A. Shepp, Optimal paths for a car that goes both forwards and backwards . ................. 367

Ai-Nung Wang, Constant mean curvature surfaces on a strip ............ 395 